\title{
Smoking and susceptibility to thyroid cancer: an inverse association with CYP1A1 allelic variants
}

\author{
Natassia E Bufalo, Janaina L Leite, Ana C T Guilhen, Elaine C Morari, \\ Fabiana Granja, Ligia V M Assumpcao and Laura S Ward
}

Laboratory of Cancer Molecular Genetics, Medical Sciences School, State University of Campinas - UNICAMP, Sao Paulo, Brazil (Requests for offprints should be addressed to L S Ward who is now at Tessalia Vieira de Camargo 126, 13084-970 Campinas, Sao Paulo, Brazil; Email: ward@unicamp.br)

\begin{abstract}
In contrast to most human malignancies, epidemiologic studies have frequently reported a reduced risk of differentiated thyroid cancer in tobacco consumers. Cytochrome P4501A1 (CYP1A1) gene variants may be related to an increased capacity to activate polycyclic aromatic hydrocarbons, producing highly reactive electrophilic intermediates that might damage DNA. Hence, the germline inheritance of a wild-type CYP1A1 gene may decrease the susceptibility for thyroid cancer. The present study was designed to investigate CYP1A1 ( $m 1$ and $m 2)$ role in thyroid tumorigenesis and its connection with GSTM1, GSTT1, GSTP1, GSTO1, and codon 72 of p53 genotypes. A total of 248 patients with thyroid nodules, including 67 benign goiters, 13 follicular adenomas, 136 papillary carcinomas, and 32 follicular carcinomas, and 277 controls with similar ethnic backgrounds were interviewed on their lifetime dietary and occupational histories, smoking habit, previous diseases, and other anamnestic data. DNA was extracted from a blood sample and submitted to PCR-restriction fragment length polymorphism assays. The wild-type CYP1A1m1 genotype was more frequent among papillary carcinoma patients $(74.26 \%)$ than in the control population (62.45\%; $P=0.0147$ ), reducing the risk for this type of cancer (odds ratio= $0.564 ; 95 \%$ confidence interval $=0.357-0.894)$. A multiple logistic regression analysis showed an inverse correlation between cigarette smoking $(P=0.0385)$ and $C Y P 1 A 1$ germline inheritance $(P=0.0237)$ with the susceptibility to papillary carcinomas. We were not able to find any correlation between smoking, clinical features, parameters of aggressiveness at diagnosis or during follow-up, and any of the GST or CYP genotypes considered separately or in different combinations. We suggest that CYP1A1 genotype might be associated with the reported reduced risk to papillary carcinomas among smokers.
\end{abstract}

Endocrine-Related Cancer (2006) 13 1185-1193

\section{Introduction}

Epidemiologic studies show that $80-90 \%$ of all cancers are related to environmental factors, such as smoking, occupational, and dietary exposures (Doll \& Peto 1981). It is well established that highly penetrant genes explain less than $5 \%$ of all cancers, but the proportion attributable to genetic polymorphisms of low penetrant genes, such as the ones involved in xenobiotic metabolism, and their interactions with environmental exposures are much less clear (Vineis 2002).

Cigarette smoking is directly responsible for approximately $90 \%$ of lung cancer cases, and is the leading cause of cancer-related deaths in the world (International Agency for Research on Cancer 2002, Levitz et al. 2004). Smoking is causally associated with oral cavity, laryngeal, oropharyngeal, and hypopharyngeal cancer and increases the risk of leukemia, sinonasal, nasopharyngeal, and esophageal cancer (International Agency for Research on Cancer 2002). Furthermore, cigarette smoking has been proved as a risk factor for developing cancer of the stomach and pancreas (International Agency for Research on Cancer 2002). Interestingly, the risk for thyroid cancer has been frequently reported as decreased in both men and women smokers, in the 
two major histological groups (papillary and follicular cancers) from all geographic regions (Mack et al. 2003).

Most procarcinogens in tobacco products require biotransformation and metabolic activation before they are able to react with DNA. This metabolic activation is generally initiated by phase I enzymes (Levitz et al. 2004). Biotransformation involves two stages: phase I, mainly controlled by enzymatic activity from cytochrome P-450 (CYP) family, and phase II, catalyzed by conjugation enzymes such as glutathione S-transferases (GST) and others. Phase I enzymes promote the activation of procarcinogens for the genotoxic electrophilic intermediaries. Phase II enzymes generally act as inactivating enzymes catalyzing the binding of intermediary metabolites into more hydrophilic products, thus facilitating their elimination (Vineis 2002). Therefore, the coordinated expression and regulation of both phases I and II enzymes and their metabolic equilibrium in the target organ cells can be important factors in determining the susceptibility to cancer as related to carcinogen exposure (Kawajiri et al. 1993, Vineis 2002).

CYP1Al gene encodes for the enzyme aryl hydrocarbon hydroxylase $(\mathrm{AHH})$, which plays a key role in phase I metabolism of estrogen and polycyclic aromatic hydrocarbons, such as those found in cigarette smoke, transforming them into carcinogens (Trell et al. 1985, Kawajiri et al. 1993). CYP1Al gene is located in chromosome $15 \mathrm{q} 22-24$ and various patterns of restriction fragment length polymorphism (RFLP) for this gene have been described. Two genetic polymorphisms of the CYPIAl gene have been reported to be associated with differences in the activity of the AHH enzyme activity - an isoleucine to valine substitution in exon 7 ( $\mathrm{m} 2$ polymorphism) and a thymine/cytosine point mutation in the MspI restriction site ( $\mathrm{m} 1$ polymorphism; Autrup 2000). Cytochrome P4501A1 (CYP1Al) $\mathrm{m} 1$ and $\mathrm{m} 2$ gene variants have been shown to be in close linkage disequilibrium and to be associated with a more inducible form of CYPIAl (Wu et al. 2002). The ensuing higher levels of the corresponding enzymes would result in an increased capacity to activate polycyclic aromatic hydrocarbons, producing highly reactive electrophilic intermediates that might damage DNA (Kawajiri et al. 1990).

We previously demonstrated that GSTT1, GSTM1, GSTP1, but not GSTO1, increased the risk of thyroid cancer (Morari et al. 2002, Granja et al. 2004a,b, 2005). We also showed that the Pro/Pro variant of codon 72 of p53, associated with a reduced p53 ability to activate apoptosis, could increase the risk for both papillary and follicular carcinomas (Granja et al.
$2004 a, b$ ). We hypothesized that the combination of increased metabolic activation and decreased detoxification, together with an impaired cellular apoptotic function could lead to a high risk of thyroid carcinogenesis. Hence, the inverse epidemiologic association observed in the literature between smoking and thyroid cancer could be related to the germline inheritance of these genotypes. In addition, we aimed to further explore the influence of these genotypes on thyroid cancer patients' outcomes.

\section{Material and methods}

\section{Patients}

This case-control prospective study was approved by the Ethics Committee of the Medical Sciences School State University of Campinas (FCM-Unicamp), and an informed written consent was obtained from all individuals. Patients consecutively referred to our Teaching Hospital - Medical Sciences School of the State University of Campinas for thyroid nodule evaluation between the years 1999 and 2005, were submitted to a careful clinical examination. The study population was composed of 80 cases of benign thyroid lesions, including 67 multinodular goiters and 13 follicular adenomas, as well as 168 cases of malignant thyroid tumors, including 136 papillary carcinomas and 32 follicular carcinomas. Differentiation stage and grade of the tumors were obtained from surgical and pathological records. Experienced pathologists of the Teaching Hospital confirmed all diagnoses. All cases were managed according to a standard protocol. The diagnosis of thyroid carcinoma was either established or suspected by fine-needle aspiration cytological study and/or by the histological analysis of thyroid tissues from patients who were referred to surgery due to thyroid nodules, presenting clinical or epidemiological suspicion of cancer. All patients were submitted to total or near-total thyroidectomy. Patients with preoperatively or intraoperatively palpable neck node metastases underwent regional neck dissection. Total body ${ }^{131}$ I scans were performed, 4-6 weeks after the operations. All patients received $100 \mathrm{mCi}{ }^{131} \mathrm{I}$. Longterm levothyroxine suppressive doses were administered following total body scan, in order to keep serum thyrotropin (thyroid-stimulating hormone; TSH) at low normal levels.

Data on lifetime occupational history, dietary habits, alcohol and drug consumption, medical history with emphasis on previous and/or present thyroid diseases, and other anamnestic data were obtained through interviews using a structured questionnaire. 
Individuals with history of previous thyroid disease, accidental or medical radiation exposure, and antecedents of other malignancies were excluded. Skin color was determined by the interviewer, in accordance with the Brazilian Institute of Geography and Statistics (http://www.ibge.gov.br/english/), but, due to the difficulty in classifying our highly heterogeneous population, we further grouped individuals into whites and non-whites . Cigarette smoking habit was recorded but, due to the limited reliable data obtained on the duration of smoking, age started smoking, quantity smoked, and years since stopped smoking, the patients were grouped in never-smokers and ever-smokers categories. This last group included individuals who consumed at least 20 packages 20 cigarettes per pack for 1 year in the last 5 years. All data, including nodule size, tumor histological features, and laboratory examinations, were confirmed in the patients' records.

\section{Follow-up}

Cancer patients were followed with periodic total body scans, serum $\mathrm{TSH}$, and thyroglobulin (Tg) measurements according to a routine follow-up protocol that included X-ray, ultrasonography, computer tomography scan, and other eventual procedures to detect distant metastasis for a period of 12-341 months (mean \pm s.D. $=30 \pm 69$ months). Patients with high serum Tg levels $(>2 \mathrm{mg} / \mathrm{dl})$ and/or suspicious total body scans were submitted to a thorough image search. We defined tumors as recurrent and/or presenting long distance metastasis according to the above parameters.

\section{Controls}

A control group of 277 healthy individuals who were matched on the basis of gender, age, and ethnicity was selected from the general population of our region, considered to have a normal iodine intake. The history obtained from these subjects included demographic and ethnic background, diet routine, lifetime occupational history, smoking history, general health conditions, and previous diseases. Individuals with history of previous thyroid disease, radiation exposure, specific environment or occupational exposure risks, and antecedents of malignancy were excluded.

\section{Identification of genotypes}

Blood specimens were obtained from all patients and control individuals. Genomic DNA was extracted from frozen specimens and leukocytes were separated from whole blood using a standard proteinase
K-phenol-chloroform protocol. CYPIAl genotypes at the $\mathrm{m} 1$ and $\mathrm{m} 2$ sites were analyzed by PCR followed by RFLP methods. Genotyping was conducted with blinding to case/control status. The primers for the $\mathrm{m} 1$ site were M1F $\left(5^{\prime}\right.$-CAG TGA AGA GGT GTA GCC GCT- $\left.3^{\prime}\right)$ and M1R (5'-TAG GAG TCT TGT CTC ATG CCT- $3^{\prime}$ ), which produce a $340 \mathrm{bp}$ fragment. The primers for $\mathrm{m} 2$ were $5^{\prime}$-TTC CAC CCG TTG CAG CAG GAT AGC C-3' and $5^{\prime}$-CTG TCT CCC TCT GGT TAC AGG AAG-3', which generate a 204 bp fragment. These fragments were amplified separately but under similar conditions as follows: $25 \mu \mathrm{l}$ volumes of a mixture containing $100 \mathrm{ng}$ DNA, $10 \mu \mathrm{M}$ of each primer, $10 \mathrm{mM}$ Tris- $\mathrm{HCl}(\mathrm{pH} 8.0), 0.1 \mathrm{mM}$ of each diNTP, $2.0 \mathrm{mM} \mathrm{MgCl}_{2}$, and $0.5 \mathrm{U}$ Taq DNA polymerase. Amplifications were carried out for 35 cycles of $94{ }^{\circ} \mathrm{C}$ for $50 \mathrm{~s}$, annealing temperatures of $60{ }^{\circ} \mathrm{C}$ for $45 \mathrm{~s}$ for $\mathrm{m} 1$ and $64{ }^{\circ} \mathrm{C}$ for $\mathrm{m} 2$ followed by $72{ }^{\circ} \mathrm{C}$ for $1 \mathrm{~min}$, with an initial denaturation step of $94{ }^{\circ} \mathrm{C}$ for $5 \mathrm{~min}$ and a final extension step of $72{ }^{\circ} \mathrm{C}$ for 10 min using a Termocycler MJ PTC-200 PCR System. The PCR fragments were visualized in ethidium bromide-stained gels. The restriction enzyme MspI was used to identify the $\mathrm{m} 1$ polymorphism according to the manufacturer's protocol (Fermentas UAB, Vilnius, Lithuania). The wild-type allele has a single band representing the entire $340 \mathrm{bp}$ fragment and the variant allele results in two fragments of 200 and $140 \mathrm{bp}$. The restriction enzyme BseMI was used to identify the $\mathrm{m} 2$ polymorphism. The wild-type allele has two fragments of 149 and $55 \mathrm{bp}$. The homozygote variant generates a single band representing the entire $204 \mathrm{bp}$ fragment and the heterozygote variant presents the three bands, according to the manufacturer's protocol (Fermentas Life Sciences). The restricted products were analyzed by electrophoresis in 3\% agarose gels containing ethidium bromide. RFLP results of $C Y P 1 A 1 \mathrm{~m} 1$ and $\mathrm{m} 2$ were confirmed by DNA sequencing of PCR products using ABI prism big dye sequencing kit (PerkinElmer, Warrington, Cheshire, UK) with an automated sequencer (ABI PRISM 377; Perkin-Elmer).

Part of the 277 control individuals and 248 thyroid nodule patients had participated in other studies previously carried out at our laboratory and were already genotyped for GSTM1, GSTT1, GSTP1, GSTO1, and 72 p53 (Morari et al. 2002, Granja et al. 2004a,b, 2005). Seventy-seven thyroid nodule patients and 66 control individuals had a complete evaluation of all the risk factors considered, including CYP1A1, GSTT1, GSTM1, GSTP1, GSTO1, and 72 p53 genotyping. 


\section{Statistical analysis}

The statistical analysis was conducted using SAS statistical software (Statistical Analysis System, version 8.1, Cary, NC, USA, 1999-2000). Associations were assessed using $2 \mathrm{X} 2$ or $2 \mathrm{Xn}$ contingency table analysis and Chi-squared $\left(\chi^{2}\right)$ or Fisher's $(F)$ exact tests were used to examine homogeneity between cases and controls regarding gender, color, previous thyroid disease, thyroid nodule size, use of medication, cigarette smoking, extent of the disease, and genotypes. The Kruskal-Wallis (KW) test was used to compare the ages among the groups. The MannWhitney or Wilcoxon tests were used to compare the age among the different genotype groups. The observed genotype frequencies were compared with those calculated using Hardy-Weinberg disequilibrium theory. The odds ratio (OR) and 95\% CI provided a measure of the strength of association, e.g. indicating the increase in odds of a given thyroid nodule, demonstrating a particular genotype compared with the control population. In order to further explore the significance of CYPIAl genotypes in different ranges of age, we performed a univariate logistic regression analysis in patients under and over 45 years old after adjusting for gender. Logistic regression was used to evaluate the effect of all genotypes, after adjusting for other potential confounders such as age, gender, color, tobacco, and both alcohol and medication consumption. A multivariate logistic regression model was applied using the nodules diagnosis (malignant or benign) and the type of tumor (papillary or follicular carcinoma) as dependent variables and all genotypes and clinical risk factors, including gender, age, and cigarette smoking as explicative variables. All tests were conducted at the $P=0.05$ level of significance.

\section{Results}

Table 1 summarizes clinical characteristics and parameters of aggressiveness at diagnosis and during follow-up of the thyroid cancer patients. There were no differences between the control individuals and the thyroid disease patients regarding age $(43 \pm 34$ vs $46 \pm$ 94 years), gender ( 84 males and 193 females vs 57 males and 191 females) and color (230 white and 47 non-white versus 203 white and 45 non-white individuals). Also, cigarette-smoking habits were similar in control individuals and patients $(28 \%$ ever smokers and $72 \%$ never smokers versus $33 \%$ ever smokers and $67 \%$ never smokers). The demographic and lifestyle characteristics of the subjects from both thyroid nodules and control groups, including alcohol consumption, red meat, vegetables and fat intake, education, and exercise were similar.

The proportion of CYPIAlm1 and CYP1Alm2 different genotypes Hardy-Weinberg equilibrium was tested in the population of 525 individuals genotyped in this study. Both variants were in equilibrium. The overall proportions of the CYPIAl genotypes in the control population and in the benign and malignant thyroid disease patients are presented in Table 2. The wild-type $C Y P 1 A 1 \mathrm{ml}$ gene was present more frequently among patients with thyroid nodules $(72.18 \%)$ than in the control individuals $(62.45 \%)\left(\chi^{2} ; P=0.0160\right)$. There was no association between CYPIAlml or CYP1A1m2 genotypes and GSTT1, GSTM1, GSTO1 or $72 p 53$ genotypes, although a trend towards an association between $C Y P 1 A 1 m 2$ and GSTM1 null genotype was observed $\left(\chi^{2} ; P=0.0535\right)$. There was no association of CYPIAl genotype and gender. When thyroid nodule patients under or over 45 years of age were analyzed separately, we observed that CYP1Al was associated to thyroid nodules only in patients over 45 years old. In these patients, $72 p 53$ variants were also more frequent than in controls $\left(\chi^{2} ; P=0.0111\right)$. The presence of a normal CYP1A1ml allele decreased the risk for a thyroid nodule by $47 \%(\mathrm{OR}=0.527 ; 95 \%$ $\mathrm{CI}=0.306-0.907$ ), while Arg/Pro or Pro/Pro variants of $p 53$ increased the risk for a thyroid nodule more than four times $(\mathrm{OR}=4.287 ; 95 \%$ confidence interval $(C I)=1.395-13.176)$. Multiple logistic regression analysis adjusted for gender confirmed CYPIAlml effect on individuals over 45 years old $(P=0.0351$; $\mathrm{OR}=0.514 ; 95 \% \mathrm{CI}=0.277-0.954$ ).

We observed that papillary carcinomas presented CYP1Al wild-type genotype more frequently (74.26\%) than controls $(62.45 \%)(P=0.0147)$. Indeed, the presence of a germline variant CYPIAlml genotype protects against the risk to develop a papillary carcinoma $(\mathrm{OR}=0.564 ; 95 \% \mathrm{CI}=0.357-0.894)$. Considering patients under and above 45 years of age, we found CYP1Alml wild-type genotype to be more frequent among thyroid cancer older patients $(78.04 \%)$ than in the controls $(60.52 \%)(P=0.0128)$. The presence of a variant $C Y P 1 A 1 \mathrm{ml}$ allele protects against thyroid cancer $(\mathrm{OR}=0.5936 ; 95 \% \mathrm{CI}=0.3869$ 0.9114). The association between CYPlAlml genotype and thyroid cancer risk is due to papillary carcinomas, as it disappeared in the relatively small group of follicular carcinomas. In addition, the association of CYP1Alml to papillary carcinomas occurs only in patients over 45 years old, who presented CYP1A1m1 wild-type allele in $82.53 \%$ of the cases, compared with only $60.52 \%$ of the controls 
Table 1 Percentage distribution of thyroid carcinoma patients according to their histology and smoke habits comparing clinical features, including age ( $\mathrm{X} \pm$ S.D. in years), gender ( $\mathrm{F}$, female; $\mathrm{M}$, male), color (W, white; NW, non-white); the presence of lymph node involvement, distant metastasis, and the stage at the time of the diagnosis; the diagnosis of recurrence and/or distant metastasis during the follow-up, and the molecular profile of papillary (PC) and follicular (FC) patients

\begin{tabular}{|c|c|c|c|c|c|}
\hline & & \multicolumn{2}{|c|}{ PC } & \multicolumn{2}{|c|}{ FC } \\
\hline & & Smoker & Non-smoker & Smoker & Non-smoker \\
\hline \multicolumn{6}{|l|}{ Clinical characteristics } \\
\hline Age $(X \pm$ s.D. $)$ & & $42 \pm 12$ & $45 \pm 16.4$ & $54.4 \pm 16.5$ & $45.7 \pm 21.2$ \\
\hline \multirow[t]{2}{*}{ Sex } & $\mathrm{F}(\%)$ & 65 & 93 & 67 & $\overline{96}$ \\
\hline & $\mathrm{M}(\%)$ & 35 & 7 & 33 & 4 \\
\hline \multirow[t]{2}{*}{ Color } & W (\%) & 89 & 82 & 83 & 82 \\
\hline & NW (\%) & 11 & 18 & 17 & 18 \\
\hline \multicolumn{6}{|l|}{ Diagnosis } \\
\hline Lymph node (\%) & & 16 & 12 & 8 & 9 \\
\hline \multicolumn{2}{|l|}{ Distant metastasis (\%) } & 2 & 3 & 14 & 12 \\
\hline \multirow[t]{2}{*}{ Stage } & I+II (\%) & 67 & 66 & 51 & 53 \\
\hline & III + IV (\%) & 33 & 34 & 49 & 47 \\
\hline \multicolumn{6}{|l|}{ Follow-up } \\
\hline \multicolumn{2}{|l|}{$\begin{array}{l}\% \text { of recurrence and/or distant } \\
\text { metastasis }\end{array}$} & 14 & 10 & 23 & 21 \\
\hline \multicolumn{6}{|l|}{ Molecular date } \\
\hline \multirow{2}{*}{ CYP1A1 } & $\mathrm{M} 1 \mathrm{~T} / \mathrm{T}(\%)$ & 73 & 76 & 67 & 54 \\
\hline & M1 T/C C/C (\%) & 27 & 24 & 33 & 46 \\
\hline \multirow[t]{2}{*}{ CYP1A1 } & M2 Ile/lle (\%) & 62 & 68 & 67 & 46 \\
\hline & M2 Ile/Val Val/Val (\%) & 38 & 32 & 33 & 54 \\
\hline \multirow[t]{2}{*}{ GSTM1 } & Positive (\%) & 47 & 64 & 80 & 61 \\
\hline & Negative (\%) & 53 & 36 & 20 & 39 \\
\hline \multirow[t]{2}{*}{ GSTT1 } & Positive (\%) & 87 & 82 & 90 & 73 \\
\hline & Negative (\%) & 13 & 18 & 10 & 27 \\
\hline \multirow[t]{2}{*}{ GSTP1 } & Ile/lle (\%) & 65 & 67 & 92 & 67 \\
\hline & Ile/Val Val/Val (\%) & 35 & 33 & 8 & 33 \\
\hline \multirow[t]{2}{*}{ GSTO1 } & Ala/Ala (\%) & 81 & 84 & 76 & 87 \\
\hline & Ala/Asp Asp/Asp (\%) & 19 & 16 & 24 & 13 \\
\hline \multirow[t]{2}{*}{ 72p53 } & Arg/Arg (\%) & 50 & 55 & 67 & 25 \\
\hline & Arg/Pro Pro/Pro (\%) & 50 & 45 & 33 & 75 \\
\hline
\end{tabular}

$(P=0.0025)$. The chance of an individual over 45 years old harboring a variant CYPIAlml allele to develop a papillary carcinoma is reduced by $64 \%$ $(\mathrm{OR}=0.4571 ; 95 \% \mathrm{CI}=0.2589-0.8068)$. Also, $72 p 53$ variants were overrepresented in the papillary carcinoma patients $(P=0.0008)$, increasing the risk for this malignancy over thrice $(\mathrm{OR}=3.522 ; 95 \%$ $\mathrm{CI}=1.686-7.357)$. A similar analysis revealed that GSTP1 variants were overrepresented in the group of follicular carcinoma patients $(72.22 \%)$ compared with control individuals $(40.39 \%)(P=0.0367)$, increasing the risk for this tumor 3.2 times $(\mathrm{OR} ; 95 \% \mathrm{CI}=1.075-9.529)$.

The multivariate logistic regression analysis of the 249 thyroid nodules and 200 control individuals data corrected for gender and age showed a significant influence of CYPIAl genotypes $(P=0.0078$; $\mathrm{OR}=1.836 ; 95 \% \mathrm{CI}=1.173-2.872$ ) on the risk for thyroid nodules. However, smoking was not an independent risk factor for thyroid cancer $(P=0.0941)$. The same multivariate logistic regression analysis model performed in the 168 malignant nodules revealed that CYP1A1 genotype was associated with the risk of papillary carcinoma $(P=0.0063, \mathrm{OR}=2.243 ; 95 \%$ $\mathrm{CI}=1.256-4.008)$ but not of follicular carcinoma. Again, smoking was neither a risk nor a protection factor against papillary $(P=0.1570)$ or follicular carcinomas $(P=0.730)$.

To further investigate the role of CYPIAl genotype and other susceptibility factors, we performed a multivariate logistic regression analysis corrected for gender and age, considering only the 77 thyroid tumors and 66 controls that had a complete evaluation of all clinical and pathologic risk factors and a complete genotyping analysis, including CYPlAlm1, CYP1A1m2, GSTM1, GSTT1, GSTO1, GSTP1, and 72p53. Only CYPlAlml $(P=0.0373)$ and smoking habits $(P=0.0348)$ had an inverse significant association with thyroid cancer risk. This association was maintained, with both CYPIA1ml $(P=0.0237)$ and smoking habits $(P=0.0385)$, in the analysis of the 47 
Table 2 Distribution of CYP1A1 ( $m 1$ and $m 2$ ), GSTM1, GSTT1, GSTP1, GSTO1 and $p 53$ codon72 wild-type and variant (homo and heterozygous) genotypes among all thyroid nodules, papillary carcinomas, follicular carcinomas, and benign nodule cases and control group individuals

\begin{tabular}{|c|c|c|c|c|c|c|c|c|c|c|c|c|c|}
\hline & \multirow{2}{*}{$\begin{array}{c}\text { Control } \\
\text { Individuals; } \\
\quad \boldsymbol{N}(\%)\end{array}$} & \multicolumn{3}{|c|}{ All thyroid nodules } & \multicolumn{3}{|c|}{ Papillary } & \multicolumn{3}{|c|}{ Follicular } & \multicolumn{3}{|c|}{ Benign } \\
\hline & & $\begin{array}{l}\text { Cases; } N \\
(\%)\end{array}$ & $\begin{array}{c}\text { OR } \\
(95 \% \mathrm{Cl})\end{array}$ & $P$ & $\begin{array}{l}\text { Cases; } N \\
(\%)\end{array}$ & $\begin{array}{c}\text { OR } \\
(95 \% \mathrm{Cl})\end{array}$ & $P$ & $\begin{array}{l}\text { Cases; } N \\
(\%)\end{array}$ & $\begin{array}{c}\text { OR } \\
(95 \% \mathrm{Cl})\end{array}$ & $P$ & $\begin{array}{l}\text { Cases; } N \\
(\%)\end{array}$ & $\begin{array}{c}\text { OR } \\
(95 \% \mathrm{Cl})\end{array}$ & $P$ \\
\hline \multicolumn{14}{|l|}{ CYP1A1m1 } \\
\hline Wild-type (T/T) & $173(62.45)$ & $179(72.18)$ & $\begin{array}{l}0.629 \\
\quad(0.431 \\
0.917)\end{array}$ & 0.0160 & $101(74.26)$ & $\begin{array}{l}0.564 \\
\quad(0.357 \\
0.894)\end{array}$ & 0.0147 & 19 (59.38) & $\begin{array}{l}1.148 \\
\quad(0.538 ; \\
2.447)\end{array}$ & 0.7210 & 59 (73.75) & $\begin{array}{l}0.5921 \\
\quad(0.3401 \\
1.031)\end{array}$ & 0.0832 \\
\hline $\begin{array}{l}\text { Polymorphic } \\
\text { (T/C-C/C) }\end{array}$ & $104(37.55)$ & $69(27.82)$ & & & $35(25.74)$ & & & $13(40.63)$ & & & $21(26.25)$ & & \\
\hline \multicolumn{14}{|l|}{ CYP1A1m2 } \\
\hline Wild-type (Ile/lle) & $180(64.98)$ & $161(64.92)$ & $\begin{array}{l}1.033 \\
(0.716 \\
1.492)\end{array}$ & 0.8618 & $90(66.18)$ & $\begin{array}{l}0.960 \\
\quad(0.620 \\
1.487)\end{array}$ & 0.8545 & $16(50.00)$ & $\begin{array}{l}2.026 \\
\quad(0.957 ; \\
4.291)\end{array}$ & 0.0650 & 55 (68.75) & $\begin{array}{l}0.8435 \\
\quad(0.4948 \\
\quad 1.438)\end{array}$ & 0.6226 \\
\hline $\begin{array}{l}\text { Polymorphic } \\
\text { (Ile/Val—Val/Val) }\end{array}$ & 97 (35.02) & 87 (35.08) & & & $46(33.82)$ & & & $16(50.00)$ & & & $25(31.25)$ & & \\
\hline \multicolumn{14}{|l|}{ GSTM1 } \\
\hline Positive & $114(55.88)$ & $124(58.49)$ & $\begin{array}{l}1.046 \\
(0.702 ; \\
1.560)\end{array}$ & 0.8246 & $70(60.87)$ & $\begin{array}{l}1.134 \\
\quad(0.703 ; \\
1.830)\end{array}$ & 0.6055 & $17(62.96)$ & $\begin{array}{l}1.282 \\
(0.553 ; \\
2.976)\end{array}$ & 0.5625 & $37(52.86)$ & $\begin{array}{l}1.130 \\
\quad(0.6552 ; \\
1.948)\end{array}$ & 0.7643 \\
\hline Negative & $90(44.12)$ & $88(41.51)$ & & & $45(39.13)$ & & & $10(37.04)$ & & & $33(47.14)$ & & \\
\hline \multicolumn{14}{|l|}{ GSTT1 } \\
\hline Positive & $157(76.96)$ & $150(78.53)$ & $\begin{array}{l}1.088 \\
\quad(0.670 \\
1.767)\end{array}$ & 0.7346 & 77 (81.05) & $\begin{array}{l}1.218 \\
\quad(0.656 ; \\
2.264)\end{array}$ & 0.5320 & $17(77.27)$ & $\begin{array}{l}0.954 \\
\quad(0.329 \\
2.765)\end{array}$ & 0.9315 & $56(75.68)$ & $\begin{array}{l}1.074 \\
\quad(0.5757 \\
2.002)\end{array}$ & 0.9494 \\
\hline Negative & $47(23.04)$ & $41(21.47)$ & & & 18 (18.95) & & & $5(22.73)$ & & & $18(24.32)$ & & \\
\hline \multicolumn{14}{|l|}{ GSTP1 } \\
\hline Wild-type (Ile/Ile) & $121(59.61)$ & $113(62.78)$ & $\begin{array}{l}0.766 \\
\quad(0.497 \\
1.180)\end{array}$ & 0.2265 & $60(64.52)$ & $\begin{array}{l}0.789 \\
\quad(0.466 \\
1.335)\end{array}$ & 0.3769 & $5(27.78)$ & $\begin{array}{l}3.200 \\
\quad(1.075 ; \\
9.529)\end{array}$ & 0.0367 & $48(69.57)$ & $\begin{array}{l}0.6456 \\
\quad(0.3598 \\
1.158)\end{array}$ & 0.1836 \\
\hline $\begin{array}{l}\text { Polymorphic } \\
\text { (Ile/Val-Val/Val) }\end{array}$ & $82(40.39)$ & 67 (37.22) & & & $33(35.48)$ & & & $13(72.22)$ & & & $21(30.43)$ & & \\
\hline \multicolumn{14}{|l|}{ GSTO1 } \\
\hline Wild-type (Ala/Ala) & $159(86.41)$ & $91(82.73)$ & $\begin{array}{l}1.486 \\
\quad(0.737 ; \\
2.997)\end{array}$ & 0.2688 & $53(84.13)$ & $\begin{array}{l}1.379 \\
\quad(0.595 ; \\
3.197)\end{array}$ & 0.4533 & $6(75.00)$ & $\begin{array}{l}2.011 \\
\quad(0.175 ; \\
13.705)\end{array}$ & 0.7002 & 32 (82.05) & $\begin{array}{l}1.391 \\
\quad(0.5542 ; \\
3.492)\end{array}$ & 0.6496 \\
\hline $\begin{array}{l}\text { Polymorphic } \\
\text { Ala/Asp-Asp/Asp } \\
\text { condon72 of p53 }\end{array}$ & 25 (13.59) & $19(17.27)$ & & & $10(15.87)$ & & & $4(25.00)$ & & & $7(17.95)$ & & \\
\hline Arg/Arg & $35(30.17)$ & $56(51.85)$ & $\begin{array}{l}2.430 \\
\quad(1.297 ; \\
4.552)\end{array}$ & 0.0056 & 37 (58.73) & $\begin{array}{l}3.522 \\
\quad(1.686 ; \\
7.357)\end{array}$ & 0.0008 & $2(25.00)$ & $\begin{array}{l}0.494 \\
\quad(0.029 \\
4.248)\end{array}$ & 0.8278 & 17 (45.95) & $\begin{array}{l}0.5084 \\
\quad(0.2381 \\
1.085)\end{array}$ & 0.1177 \\
\hline Pro/Pro+Arg/Arg & $81(69.83)$ & $52(48.15)$ & & & $26(41.27)$ & & & $6(75.00)$ & & & 20 (54.05) & & \\
\hline
\end{tabular}


papillary carcinomas that had all genotypes studied, but not in the follicular carcinomas.

There were no differences between thyroid follicular adenomas and carcinomas concerning any of the studied risk factors. There was no association between any of the studied genotypes, either considered alone or in combination, and the histology or any parameter of aggressiveness at diagnosis or during follow-up.

\section{Discussion}

A continuous increase in the incidence of thyroid cancer has been registered during the past decades in Brazil as well all over the world (Parkin et al. 1997, Haselkorn et al. 2000, Liu et al. 2001, Burgess 2002, Coeli et al. 2005, Reynolds et al. 2005). This fact is certainly due in part to the larger use of better diagnostic tools such as the cytology obtained through fine-needle aspiration biopsy and ultrasonography. However, the incidence continues to increase in welldeveloped regions, and the major difficulty in understanding the reason is the fact that the causes for welldifferentiated thyroid cancer are not yet fully known. Likewise, other tumors, thyroid cancer is related to environmental factors but, in addition to the exposure to ionizing radiation, no other physical, chemical, or biologic factor has been proven to cause thyroid cancer thus far (Ron et al. 1995, Jacob et al. 2006).

A series of polymorphisms in germline DNA have been investigated in an effort to delineate polygenic models of cancer susceptibility. Such models are particularly interesting in thyroid cancer. Indeed, thyroid nodules are detected by ultrasonography in up to $67 \%$ of the population, but few are malignant and require surgical treatment (Castro \& Gharib 2005). Therefore, screening tools designed to identify individuals at risk for thyroid cancer, select persons for specific preventive or diagnostic interventions, and determine which patients with thyroid nodules are most likely to benefit from specific therapies, are an upmost necessity. Genes involved in xenobiotic metabolism may be interesting for this sort of screening. The interindividual variability in the ability to biotransform potentially toxic substances has been associated with greater or lesser susceptibility to toxicity or cancer risk. Individuals incapable of adequately detoxifying a toxic agent or a metabolic carcinogen would undergo greater DNA and cell damage, with the formation of adducts or chemical elements bound to the DNA and protein macromolecules, causing genomic instability. Consequently, these individuals would be at greater risk of developing tumors (Wogan et al. 2004).
A series of studies conducted in different populations have found a correlation between CYPIAl polymorphisms and different types of cancer. Consistent evidences for association between CYP polymorphisms and many human tumors have been reported, generally connecting a higher activity of phase I oxidative pathway to enhanced carcinogenesis (Vineis 2002, Agundez 2004). Controversial findings suggest that colorectal and prostate cancers may be associated with $C Y P$ polymorphisms, whereas no evidences for a relevant association with breast or bladder cancers have been reported (Vineis 2002, Agundez 2004). Our data demonstrated an inverse significant association between CYPIAlm1 and smoking habits in the risk of thyroid cancer. To our knowledge, this is the first report on CYP1A1 influence on thyroid tumorigenesis. Interestingly, we found CYPIAl wild-type allele to be more frequent both in thyroid nodules and in papillary carcinomas than in the control population, suggesting that cigarette smoking and other metabolites that depend on CYPIAl activation are neither implicated in the risk of thyroid goitrogenesis nor in the following processes that lead to thyroid malignancy. This observation fits very well with the epidemiologic observations that were not able to associate cigarette smoking with thyroid cancer or which even found a lower risk for thyroid cancer among smokers. Indeed, 12 out of 13 case-control studies that examined the association between cigarette smoking and thyroid cancer found the risk of thyroid cancer to be decreased by $40 \%$ among smokers (Mack et al. 2003). Cohort studies, including a recent prospective Canadian one, were not able to demonstrate any association between smoking history and the risk of thyroid cancer (Iribarren et al. 2001, Navarro Silvera et al. 2005).

On the other hand, our data demonstrated that CYP1Al influenced thyroid nodules and papillary carcinoma risk only in individuals over 45 years old, suggesting that the pathogenesis of thyroid tumors could be related to the continuous exposure to one or more carcinogenic products metabolized by phase I oxidative enzymes. Since the enzymes encoded by detoxifying genes are substrate and tissue specific, and they act in conjunction, it is very difficult to explain the role each one plays. Different environmental factors could also be implicated in the pathogenesis of follicular carcinomas, explaining why we were not able to establish any significant association between CYP genotypes, smoking, and the risk for this type of tumor. However, the relatively small number of follicular carcinomas included in this study prevents any further consideration.

We did not find any additive or combined effect of the phase I and phase II genes studied in the 
risk for thyroid cancer or in the patients outcome, but we observed a distinct profile of susceptibility genes in different ranges of ages, confirming our previous observations on the role of 72 p53 and GSTs in thyroid cancer risk (Morari et al. 2002, Granja et al. 2004a,b, 2005).

In conclusion, we demonstrated an inverse association between germline CYPIAl inheritance and smoking with the risk of thyroid nodules and papillary carcinomas that may help to explain the reduced risk of differentiated thyroid cancer in tobacco consumers observed in epidemiologic studies.

\section{Acknowledgements}

We are grateful to Professors Denise Wittman-Zantut and Elizabeth Pavin for helping us to obtain some of the patients with thyroid benign hyperplasia included in this study. We also acknowledge the skillful contribution of Helio Akinori Kitagaki Junior and Rafael Souza Queiroz to the genotyping assays. This study was supported by the State of São Paulo Research Foundation - FAPESP, under the grant numbers 03/02309-7 and 03/11026-9. The authors declare that there is no conflict of interest that would prejudice the impartiality of this scientific work.

\section{References}

Agundez JA 2004 Cytochrome $P 450$ gene polymorphism and cancer. Current Drug Metabolism 5 211-224.

Autrup H 2000 Genetic polymorphisms in human xenobiotic metabolizing enzymes as susceptibility factors in toxic response. Mutation Research 464 65-76.

Burgess JR 2002 Temporal trends for thyroid carcinoma in Australia: an increasing incidence of papillary thyroid carcinoma (1982-1997). Thyroid 12 141-149.

Castro MR \& Gharib H 2005 Continuing controversies in the management of thyroid nodules. Annals of Internal Medicine 142 926-931.

Coeli CM, Brito AS, Barbosa FS, Ribeiro MG, Sieiro AP \& Vaisman M 2005 Incidence and mortality from thyroid cancer in Brazil. Arquivos Brasileiros de Endocrinologia e Metabolismo 49 503-509.

Doll R \& Peto R 1981 The causes of cancer: quantitative estimates of avoidable risks of cancer in the United States today. Journal of the National Cancer Institute 66 1191-1308.

Granja F, Morari J, Morari EC, Correia LA, Assumpcao LVM \& Ward LS $2004 a$ GST profiling may be useful in the screening for thyroid nodule malignancy. Cancer Letters 209 129-137.
Granja F, Morari J, Morari EC, Correa LA, Assumpcao LVM $\&$ Ward LS 2004b Proline homozygosity in codon 72 of p53 is a factor of susceptibility for thyroid cancer. Cancer Letters 210 151-157.

Granja F, Morari EC, Assumpcao LVM \& Ward LS 2005 GSTO polymorphism analyses in thyroid nodules suggest that GSTO1 variants do not influence the risk for malignancy. European Journal of Cancer Prevention 14 277-280.

Haselkorn T, Bernstein L, Preston-Martin S, Cozen W \& Mack WJ 2000 Descriptive epidemiology of thyroid cancer in Los Angeles County, 1972-1995. Cancer Causes Control 11 163-170.

International Agency for Research on Cancer 2002 Tobacco Smoke and Involuntary Smoking. IARC Monographs on the Evaluation of Carcinogenic Risk. vol 83. Washington DC: IARC Press.

Iribarren C, Haselkorn T, Tekawa IS \& Friedman GD 2001 Cohort study of thyroid cancer in a San Francisco Bay area population. International Journal of Cancer 93 745-750.

Jacob P, Bogdanova TI, Buglova E, Chepurniy M, Demidchik Y, Gavrilin Y, Kenigsberg J, Meckbach R, Schotola C, Shinkarev S et al. 2006 Thyroid cancer risk in areas of Ukraine and Belarus affected by the Chernobyl accident. Radiation Research 165 1-8.

Kawajiri K, Nakachi K, Imai K, Yoshii A, Shinoda N \& Watanabe J 1990 Identification of genetically high risk individuals to lung cancer by DNA polymorphisms of the cytochrome P450IA1 gene. FEBS Letters 263 131-133.

Kawajiri K, Nakachi K, Imai K, Watanabe J \& Hayashi S 1993 The CYP1A1 gene and cancer susceptibility. Critical Reviews in Oncology and Hematology 14 77-87.

Levitz JS, Bradley TP \& Golden AL 2004 Overview of smoking and all cancers. Medical Clinics of North America 88 1655-1675.

Liu S, Semenciw R, Ugnat AM \& Mao Y 2001 Increasing thyroid cancer incidence in Canada, 1970-1996: time trends and age-period-cohort effects. British Journal of Cancer 85 1335-1339.

Mack WJ, Preston-Martin S, Dal Maso L, Galanti R, Xiang M, Franceschi S, Hallquist A, Jin F, Kolonel L, La Vecchia C et al. 2003 A pooled analysis of case-control studies of thyroid cancer: cigarette smoking and consumption of alcohol, coffee, and tea. Cancer Causes Control 14 773-785.

Morari EC, Leite JLP, Granja F, Assumpcao LVM \& Ward LS 2002 The null genotype of glutathione S-transferase M1 and T1 locus increases the risk for thyroid cancer. Cancer Epidemiology Biomarkers \& Prevention 11 1485-1488.

Navarro Silvera SA, Miller AB \& Rohan TE 2005 Risk factors for thyroid cancer: a prospective cohort study. International Journal of Cancer 116 433-438.

Parkin D, Whwlan S, Ferlay J, Raymond L \& Young J 1997 Cancer Incidence in Five Continents. vol VII. IARC Science Publishing. 
Reynolds RM, Weir J, Stockton DL, Brewster DH, Sandeep TC \& Strachan MW 2005 Changing trends in incidence and mortality of thyroid cancer in Scotland. Clinical Endocrinology 62 156-162.

Ron E, Lubin JH, Shore RE, Mabuchi K, Modan B, Pottern LM, Schneider AB, Tucker MA \& Boice JD, Jr 1995 Thyroid cancer after exposure to external radiation: a pooled analysis of seven studies. Radiation Research 141 259-277.

Trell L, Korsgaard R, Janzon L \& Trell E 1985 Distribution and reproducibility of aryl hydrocarbon hydroxylase inducibility in a prospective population study of middle-aged male smokers and nonsmokers. Cancer 56 1988-1994.

Vineis P 2002 The relationship between polymorphisms of xenobiotic metabolizing enzymes and susceptibility to cancer. Toxicology 181-182 457-462.

Wogan GN, Hecht SS, Felton JS, Conney AH \& Loeb LA 2004 Environmental and chemical carcinogenesis. Seminars in Cancer Biology 14 473-486.

Wu MT, Lee JM, Wu DC, Ho CK, Wang YT, Lee YC, Hsu HK \& Kao EL 2002 Genetic polymorphisms of cytochrome P4501A1 and oesophageal squamous-cell carcinoma in Taiwan. British Journal of Cancer 87 529-532. 